\title{
Auditors' liability with overcompensation and reputation losses
}

\author{
Jochen Bigus
}

Published online: 15 February 2011

(C) Springer-Verlag 2011

\begin{abstract}
This paper contributes to the theoretical literature by analyzing the effect of two empirically relevant characteristics of auditor liability. First, we endogenize a loss of reputation whenever an accounting scandal occurs, even if no lawsuit is brought against the auditor. Second, we model the fact that damage compensation payments usually exceed the investors' social loss (overcompensation) since some investors benefit from wrong financial statements. Under a vaguely defined negligence rule, both phenomena tend to induce excessive care when investors are sufficiently likely to bring a lawsuit. If reputation losses are sufficiently high, a Nash equilibrium in pure strategies evolves where investors do not sue and auditors do not exert suboptimal care. Litigation costs are then saved. A properly defined liability cap mitigates excessive care caused by overcompensation or reputation losses.
\end{abstract}

Keywords Auditors' liability $\cdot$ Reputation loss · Overcompensation · Negligence

\section{Introduction}

Even though it has been known for many years that auditors are concerned about protecting their reputation capital (Benston 1975; Watts and Zimmermann 1983; Lim and Tan 2008) and that reputation losses might be substantial, the theoretical literature

For helpful comments and discussions, I would like to thank two anonymous referees, the editor in charge (Dirk Simons), Giuseppe Dari Mattiacci, Hans-Bernd Schäfer, Ulf Schiller and workshop participants at University of Hamburg, University of Frankfurt/Main and at the European Association of Law and Economics meeting 2009 in Rome.

\footnotetext{
J. Bigus $(\varangle)$

Institute of Accounting and Control, University of Berne, Engehaldenstrasse 4, 3012 Bern, Switzerland e-mail: bigus@iuc.unibe.ch
} 
has not yet addressed this matter in any depth. To our knowledge, no precise data on auditors' reputation losses exists yet, even though such losses may be significant. As an extreme example, Arthur Andersen lost so much reputation in the aftermath of the Enron scandal that the business folded after admitting on January 10, 2002 that they had destroyed audit files. Weber et al. (2008) find that after the events pertaining to the ComROAD accounting scandal, the number of clients that abandoned KPMG doubled in 2002 relative to the three previous years, even though no lawsuit has been filed against the audit firm. It is worth pointing out that reputation losses cannot merely be seen as a kind of legal cost since (a) they may even occur in the absence of litigation and (b) their weight seems to be considerably higher than that of fines or damage payments (Karpoff et al. 2008). Considering this evidence on reputation losses, the claim asserted by practicing auditors in the USA that legal liability is excessive may be understandable (O’Malley 1993).

Our analysis suggests that both the prospects of reputation gains and the threat of reputation losses significantly affect not only the investors' incentives to bring a lawsuit but also the auditors' incentives to take due care. In the model we interpret reputation losses to be the present value of future rents from auditing and non-auditing services that are lost due to an accounting scandal. We assume that the auditor loses his reputation if damage occurs due to a material error in the audited financial statement. In an analogous way, the auditor is able to gain in reputation if no damage occurs.

Reputation losses are beneficial in the sense that auditors may even have a proper incentive to take care in the absence of strong suing incentives. It transpires that when reputation losses outside litigation are sufficiently high, a Nash equilibrium in pure strategies exists where investors do not sue and, still, auditors do not exert suboptimal care. This result adds to the previous audit literature (e.g., Antle 1982) which determines Nash equilibria in mixed strategies, implying that litigation costs and inefficient auditor care are expected with a certain probability in equilibrium.

Our analysis suggests that a properly defined liability cap is desirable if reputation effects induce auditors to exert excessive care. So far, the literature points out that a liability cap might be useful when auditors are risk-averse and when there is limited insurability of damages (London Economics and Ewert 2006).

Since reputation concerns are likely to drive auditors' incentives, they should be addressed in the ongoing debate on whether statutory auditors' liability should be capped in the USA (Committee on Capital Markets Regulation 2006). The recommendation of the European Commission (2008) to introduce a liability cap might also be justified by the existence of reputation effects. However, the European Commission puts forward different arguments and stresses the size and the limited insurability of damage claims and the threat of another big audit firm collapsing. ${ }^{1}$

1 As of September 2005, there were 25 outstanding claims against audit firms (20 in the USA and 5 in Europe), with damages sought or estimated losses exceeding US \$1 billion (London Economics and Ewert 2006, pp. 82-88). 
The literature on auditor liability does not address reputation concerns either, but focuses instead on other aspects. ${ }^{2}$ As an exception, Ewert (1999) assumes that the auditor might lose his reputation if he is found negligent in litigation. Considering the empirical evidence quoted above, we think it is also plausible to assume that an auditor may lose his reputation if he is involved in an accounting scandal, but cannot be found negligent. This is why we believe that a Nash equilibrium in pure strategies may exist. A second main difference is that we endogenize the loss of reputation. Third, we consider the issue of overcompensation. Datar and Alles (1999) analyze how auditors create a reputation in an auditor-manager monitoring relationship, whereas we focus on the auditor-investor relationship and stress the reputation with regard to investors. Furthermore, we allow for overcompensation.

Overcompensation is known from the law and economics literature on "pure economic losses" (e.g., Shavell 1987). This literature distinguishes pure economic losses from real losses. With real losses, individual damage equals the social damage. For instance, if a neighbor's house burns down, the neighbor's loss equals the loss to society.

In contrast, with pure economic losses individual damage exceeds the social damage. When an auditor wrongly testifies a wrongful report, some investors lose out because they would have paid less if the financial report had been correct. But there may be investors who benefit from the error because they are able to sell their shares at a price exceeding the "true" value. As a net effect, losses and gains will cancel each other out to a large extent. Still, there will be a social loss since investment decisions are generally distorted (Dari Mattiacci and Schäfer 2007). This means that the damage to investors who have suffered a loss from a wrongful financial report usually exceeds by far the associated social damage. We are not aware of any jurisdiction where benefiting investors are required to transfer their gains from wrongful financial statements to losing investors. For this reason, from an economics perspective, it is essential to distinguish between individual and social losses, especially in the case of third-party liability which we observe, for instance, in the USA. Overcompensation is especially pronounced with large damage claims and unlimited liability. Unfortunately, we were unable to find any empirical data on the extent to which individual and social losses precisely differ. ${ }^{3}$

\footnotetext{
2 This literature focuses on the effect of performance-based audit fees (Radhakrishnan 1999), compares several and joint liability and proportionate liability (Hillegeist 1999), and asks how the possibility to settle a lawsuit affects auditors' care in the first place (Boritz and Zhang 1997, Smith and Tidrick 1998, Zhang and Thoman 1999). Balachandran and Nagarajan (1987) and Ewert et al. (2000) address the issue of auditor liability insurance. Dye (1993) analyzes the effect of limited liability due to auditors' limited wealth. The issue of vaguely defined standards of due care is addressed by Ewert (1999) and Willekens and Simunic (2007). Schwartz (1997) argues that shareholders may overinvest since in bad states of nature they are able to sue the auditor for compensation, and then auditors may exert excessive care. Pae and Yoo (2001) show that a stricter liability regime reduces the owner's investment in the quality of the firm's internal control system.

3 The only empirical study related to pure economic losses by Niblett et al. (2008) analyzes a different question, namely whether common law converges in commercial areas in the USA based on state-court appellate decisions involving the application of the rule of pure economic loss.
} 
Note that in secondary markets, overcompensation is a given ${ }^{4}$ matter of fact in auditors' liability due to the issue of pure economic losses. There are papers unassociated with auditor liability that suggest introducing punitive damages in order to design optimal liability rules (such as, for instance, in Polinsky and Rubinfeld 1996). Punitive damages are a regulatory option whereas overcompensation is not.

It transpires that overcompensation induces excessive care with a vague negligence rule if investors are sufficiently likely to bring a lawsuit. A properly defined liability cap then induces efficient care.

Our model has implications for the regulation of auditors' liability. If investors are likely to bring a lawsuit, in the event of overcompensation or strong reputation effects the regulator might want to introduce a liability cap. If the regulator wants to avoid costly litigation while retaining strong incentives for auditors to take care, he might consider increasing rents in the audit market, for instance, by limiting competition. This approach is only desirable if the dead-weight loss of monopoly or oligopoly power is outweighed by savings in litigation costs and the efficiency gains of increased auditors' care. This proposal also stands in contrast to the ongoing public debate on constraining the auditor's business, and may therefore not be politically feasible at present.

We proceed as follows. Section 2 deals with overcompensation, and Sect. 3 investigates reputation effects in the context of auditor liability. Section 4 concludes the paper.

\section{Overcompensation}

\subsection{Model}

We consider a publicly traded firm with a materially incorrect financial report. If a risk-neutral auditor fails to detect the error, risk-neutral investors will make wrong investment decisions that induce a social loss of $D$ to investors. ${ }^{5}$ The auditor earns a flat fee ${ }^{6}$ for his audit that meets his participation constraint. Without loss of generality, the interest rate is assumed to be zero. Following Shavell (1987), we look at unilateral and unlimited liability. There is a probability $p$ that the auditor will not detect the mistake and damage occurs. The probability of damage, $p$, depends on the auditor's

\footnotetext{
4 The regulator would be able to mitigate or even to avoid overcompensation by requiring investors who benefit from a wrong audit to transfer their gains to the losing investors. However, we do not observe such rules, possibly due to transaction costs or for legal reasons. As such, overcompensation is a given matter of fact.

5 In the literature, damage is specified as the efficiency loss to investors from wrongful auditing. Correct audits allow investors to update beliefs in ex-ante unknown project types, which increases the investors' net present value. For simplicity, we skip this specification and refer instead to Pae and Yoo (2001, p. 336).

6 Contingent audit fees are prohibited or inconsistent with the professional code of conduct in most countries. Thus, many theoretical papers on auditors' liability employ this assumption; see Ewert (1999, p. 184).
} 
level of care, $x$ :

$$
\begin{aligned}
& p=p(x) \text { with } x \geq 0 \text {; with } 0 \leq p \leq 1, \quad p(x=0)=1, \quad p^{\prime}(x)<0, p^{\prime \prime}(x)>0 \\
& \quad \text { and } p \rightarrow 0 \text {, if } x \rightarrow \infty .
\end{aligned}
$$

We thus assume that the probability of damage decreases as the auditor's level of care increases, albeit at diminishing rates. The auditor also bears the direct costs of performing the audit. For simplicity, these costs equal the level of care $x$. Auditing is socially efficient if the direct costs of care are lower than the reduction in expected damages. The welfare gain is reflected by:

$$
Y=(1-p(x)) D-x .
$$

Let us assume $Y>0$. With the socially desirable level of care, $x=x^{*}$, marginal gains equal the marginal costs of auditing. Thus,

$$
Y^{\prime}(x)=0 \text { for } x=x^{* 7}
$$

Apparently, a negligence rule defining the due standard of care to be precisely $x^{S}=x^{*}$ will induce an auditor to choose the efficient level of care if investors bring a lawsuit for sure (Shavell 1987). However, so far we have neglected a game-theoretic setting and have not considered overcompensation.

In the appendix, we show that auditor liability implies overcompensation because individual damage exceeds the social damage. The difference between individual and social damage is distributional in nature. When an auditor wrongly testifies a report with inflated earnings, some investors lose out because they would have paid less for the firm's share if the financial report had been correct. But there are some investors who benefit from the error because they are able to sell their shares at a price exceeding the "true" value. As a net effect, losses and gains will cancel each other out to a large extent.

Overcompensation is simply accounted for by assuming that the (expected) damage payments to the investors who suffer loss shall amount to $\bar{D}=m D$ with $m>1$, where $D$ denotes the social (net) damage of all investors. Factor $m$ reflects the level of overcompensation. Note that $m$ is not 'punitive damage' charged by a court, but simply a consequence of pure economic loss and of the fact that winning investors are not obliged to transfer their gains to losing investors in case of a wrong financial statement.

We assume that the standard of due care is not precisely (vaguely) defined. With a precise standard, the auditor exactly knows ex ante the "red line" that separates negligent from non-negligent behavior. In the auditing business, however, the red line is not always clear. Often, courts have to assess ex post whether or not the auditor has exerted due care. Thus, from an ex ante point of view, levels of care exist where it is unclear whether or not the auditor has met the due level.

\footnotetext{
7 The second-order condition is met because of (1). For simplicity, we do not address the second-order conditions in the following. They are all met, however.
} 
Let us assume that with a level of care of at least $x_{H}$, the auditor will certainly not be held liable. For lower care levels $\left(x<x_{H}\right)$, the auditor does not know for sure ex ante how the court will decide ex post. We can capture this uncertainty by a probability function $F=F(x)$.

$$
F(x)\left\{\begin{array}{ll}
\in(0,1], & 0 \leq x<x_{H} \\
=0, & x \geq x_{H}
\end{array} \text { with } F^{\prime}(x)<0 \text { for } x<x_{H}{ }^{8}\right.
$$

In order to rule out several interior optima, let us assume that $F(x)$ is either strictly concave or strictly convex or linear. In the following, we assume that the efficient level (which will be exactly determined expost) is located in the "fuzzy" zone: $0<x^{*}<x_{H}$. This assumption is plausible if courts try hard to define the standard of due care to be the efficient level of care. Due to a lack of information, however, they may sometimes assess a higher or lower level.

Investors will not sue the auditor for sure. The decision to bring a lawsuit depends on the transaction costs $T(T>0)$ associated with litigation, such as lawyer's and court fees, coordination and opportunity costs. ${ }^{9}$

Note that investors have only the two options- "lawsuit" or "no lawsuit"-in the event of damage occurring. Investors do not know the level of care chosen by the auditor. Auditors have to decide on the level of care before investors sue. Thus, investors and auditors choose their actions without observing the actions of the other party, which is similar to a setting with simultaneous actions. Otherwise, all parameters are common knowledge.

As a benchmark case, we first analyze a setting in which investors sue for sure. Investors sue for sure when the transaction costs of a lawsuit are sufficiently small or the expected benefits are sufficiently large. This scenario tends to reflect the US legal environment where lawyer's fees can be based on performance and where it is relatively easy to file class action lawsuits. The subsequent game-theoretical analysis in Sect. 2.3, on the other hand, tends to address the circumstances in Europe.

\subsection{Investors bring a lawsuit for sure}

\subsubsection{General characterization of $F(x)$ and $p(x)$}

We first perform the analysis without specifying the slope of $F(x)$ before turning to the case where $F(x)$ is linear. The auditor's total costs are then given by

$$
C(x)= \begin{cases}x+F(x) p(x) m D, & x<x_{H} \\ x, & x \geq x_{H}\end{cases}
$$

\footnotetext{
8 In contrast to Ewert (1999) and Schwartz (1997), we assume that at some level of care $x_{H}$ there is no doubt that the auditor is not negligent.

9 These costs largely depend on the legal provisions pertaining to litigation: for instance, whether and in which way class actions are possible and whether contingent fees for lawyers are permitted.
} 
where the first derivative yields

$$
C^{\prime}(x)= \begin{cases}1+\left[F^{\prime}(x) p(x)+F(x) p^{\prime}(x)\right] m D, & x<x_{H} \\ 1, & x \geq x_{H} .\end{cases}
$$

Recall that $p(x)$ is the probability that a material mistake and damage occur. $F(x)$ is the probability that the court will find the auditor negligent given that damage has occurred. Note that the auditor faces no negligence when he meets the level $\hat{H}$. We can easily see from (5) and (6) that there is either an individual corner optimum $\hat{x}=x_{H}$ or an interior optimum $0<\hat{x}<x_{H}$.

According to (2), the social cost function is $K(x)=x+p(x) D$ with first derivative

$$
K^{\prime}(x)=1+p^{\prime}(x) D
$$

The factor 1 stands for the marginal costs of additional care, the term $p^{\prime}(x) D$ reflects the social marginal benefits in form of reduced expected damages. Note that both $p^{\prime}(x)$ and $F^{\prime}(x)$ have a negative sign for $x<x_{H}$. In the absence of overcompensation $(m=1)$, the auditor's individual optimum will not exceed the social optimum if holds:

$$
\left|F^{\prime}(x) p(x)+F(x) p^{\prime}(x)\right| D \leq\left|p^{\prime}(x)\right| D .
$$

If the left side in (8) is lower than the right side, then the individual marginal benefits of additional care are lower than the social marginal benefits, implying suboptimal care. Now let us introduce overcompensation, that is, on the left side of (8) we replace $D$ by $m D$. There will be excessive care with a sufficient level of overcompensation if the following holds

$$
m>\underline{m}=\frac{\left|p^{\prime}(x)\right|}{\left|F^{\prime}(x) p(x)+F(x) p^{\prime}(x)\right|} .
$$

Proposition 1 If investors sue for sure and there is unlimited liability and (8) holds, sufficient levels of overcompensation with $m>\underline{m}$ will cause excessive care (see (9)).

\subsubsection{Linear characterization of $F(x)$}

With general distribution functions we are unable to precisely determine the efficient level of care or the auditor's optimum. Let us, therefore, assume

$$
p(x)=\frac{1}{1+x} \text { with } x \geq 0
$$

Consequently, the socially desirable level of care, $x=x^{*}$, is defined as:

$$
Y^{\prime}(x)=0 \text { for } x=x^{*} \text { with } x^{*}=\sqrt{D}-1 \text {. }
$$


Let us assume $D \geq 1$ such that $Y>0$. Further, for tractability, we assume that $F(x)$ is uniformly distributed:

$$
F(x)=\left\{\begin{array}{ll}
\frac{x_{H}-x}{x_{H}}, & 0 \leq x<x_{H} \\
0, & x \geq x_{H}
\end{array} \text { with } F^{\prime}(x)<0 \text { for } x<x_{H} .\right.
$$

Let us now turn to the analysis. If the auditor knows for sure that investors will bring a lawsuit, the auditor's total costs are given by

$$
C(x)=\left\{\begin{array}{ll}
x+\frac{\left(x_{H}-x\right) m D}{x_{H}(1+x)} \\
x
\end{array} \quad \text { with } \quad C^{\prime}(x)= \begin{cases}1-\frac{\left(1+x_{H}\right) m D}{x_{H}(1+x)^{2}}, & x<x_{H} \\
1, & x \geq x_{H} .\end{cases}\right.
$$

There are two local individual cost minima at most. One of these is the corner optimum, $\hat{x}=x_{H}$. A second one could be located in the range $x<x_{H}$, minimizing $C(x)$. Hence, the individual global cost minimum is $\hat{x}^{h}$ with:

$$
\hat{x}^{h} \in \begin{cases}\hat{x}_{1}=\sqrt{\frac{\left(1+x_{H}\right) m D}{x_{H}}}-1, & \text { if } \hat{x}_{1}<x_{H} \wedge C\left(\hat{x}_{1}\right) \leq C\left(x_{H}\right) \\ x_{H}, & \text { otherwise }\end{cases}
$$

with $x_{H}>x^{*}$ and $\hat{x}_{1}>x^{*}=\sqrt{D}-1$ since $m>1$.

If investors sue for sure, the auditor will exert excessive care, partly due to the vaguely defined standard of due care. An additional unit of care in the range $x<x_{H}$ reduces both the probability of damage occurring and the probability of being held liable by court.

With the linear specification of $F(x)$ there will be excessive care even in the absence of overcompensation $(m=1)$. Even though overcompensation in this case does not affect the structure of the equilibrium, it might have significant economic effects because it makes the problem of excessive care more serious and affects the social loss due to distorted auditor's incentives. Unfortunately, we lack the empirical data showing the extent of the severity of the problem of overcompensation. Still, to make the point clearer, let us look at an example where losing investors suffer a loss of 36 (million) from the disclosure of the falsely audited financial statement, while other investors gain 32. The social loss is $D=4$ such that we have $m=9$. According to (11), the efficient level of auditor care would be $x^{*}=1$. With $x_{H}=6$, the individual optimum is $\hat{x}^{h}=5.48$, whereas it is 1.16 without overcompensation. With overcompensation, the social value of the audit is even negative $\left(Y\left(\hat{x}^{h}=5.48\right)=-2.10\right.$, see (13)), whereas it is still positive without overcompensation $\left(Y=\left(\hat{x}^{h}=1.16\right)=0.98\right)$, with the efficient level being $Y\left(x^{*}\right)=1$. The social value of an audit decreases with a higher level of overcompensation $(m)$.

A properly defined liability cap avoids the problem of excessive care. With limited liability we replace $m D$ by $L$ in (14). Efficient care will be achieved if the following holds:

$$
x^{*}=\hat{x}_{1} \Leftrightarrow \sqrt{\frac{\left(1+x_{H}\right) L}{x_{H}}}-1=\sqrt{D}-1 \Leftrightarrow L=L^{*}=\frac{x_{H} D}{1+x_{H}}<D .
$$


Proposition 2 If overcompensation tends to aggravate the problem of excessive care under a vague standard of due care, a properly defined liability cap with $L=L^{*}<D$ provides the efficient level of care.

We are also able to achieve efficient care with a liability cap $L^{*}$ in case where $F(x)$ and $p(x)$ are generally defined and where there is excessive care due to overcompensation, that is $m>\underline{m}$ holds (see (9)):

$$
L=L^{*}=\frac{\left|p^{\prime}(x)\right| D}{\left|F^{\prime}(x) p(x)+F(x) p^{\prime}(x)\right|} .
$$

\subsection{Game-theoretical analysis}

If auditors knew for sure that investors will not sue, the auditor's optimal response can be derived from minimizing

$$
C(x)=x \text { for } x \geq 0,
$$

where the obvious solution is $\hat{x}^{l}=0$ and the probability of damage equals $p(x=0)=1$. Thus, overcompensation does not matter when investors do not bring a lawsuit.

Proposition 3 There is an equilibrium with two subcases depending on the size of transaction costs $T$.

Case 1: With high investors' transaction costs

$$
T \geq F\left(\hat{x}^{l}(\sigma=0)\right) m D=m D
$$

there is a Nash equilibrium in pure strategies where investors do not sue and the auditor performs zero care $\hat{x}^{l}=0$ with $F\left(\hat{x}^{l}=0\right)=1$, implying an efficiency loss of $Y\left(x^{*}\right)-Y\left(\hat{x}^{l}\right)$.

Case 2: With low investors' transaction costs, that is, if (18) does not hold, there is a Nash equilibrium where investors sue with probability $\sigma^{*}=1$ if $\hat{x}(\sigma=1) \leq \underline{x}$ and with probability $\sigma^{*}<1$ if $\hat{x}(\sigma=1)>\underline{x}$ with

$$
\underline{x}=x_{H}-x_{H} T / m D \text {. }
$$

The auditor chooses a pure strategy where the care level is

$$
\hat{x}\left(\sigma^{*}\right)=\sqrt{\frac{\sigma^{*}\left(1+x_{H}\right) m D}{x_{H}}}-1,
$$

which implies excessive care if - ceteris paribus - the level of overcompensation is sufficiently large, $m>\frac{x_{H}}{\sigma^{*}\left(1+x_{H}\right)}$. The efficiency loss amounts to $\sigma^{*} T+Y\left(x^{*}\right)-Y\left(\hat{x}\left(\sigma^{*}\right)\right)$.

Proof Case 1: The auditor's optimal response, given that investors do not bring a lawsuit is given by (17). Case 2: see appendix. 
Even though the technical structure of equilibrium in cases 1 and 2 is known from the literature, the impact of overcompensation is noteworthy from an economics point of view. A higher level of overcompensation (higher $m$ ) makes investors more willing to sue (see (18)), but also increases the auditor's level of care (see (20)). With sufficiently high levels of overcompensation there is excessive care in equilibrium and the social value of an audit may even be negative (see example in Sect. 2.2.2).

\subsection{Discussion}

Game-theoretical analysis with limited liability. Limited liability affects not only the threshold levels for investors to sue (see condition (18)) but also the auditor's level of care (see (20)) (replace $m D$ by $L$ ). Limited liability is only desirable if (a) transaction costs are sufficiently low such that case 2 still occurs and if (b) the auditor exerts excessive care in case 2 with unlimited liability. When $\hat{x}(\sigma=1) \leq \bar{x}$ holds, the efficient level of care is chosen with a liability cap defined as in (15). With $\hat{x}(\sigma=1)>\bar{x}$, the efficient level of care can be achieved if the following holds:

$$
\begin{gathered}
\hat{x}\left(\sigma^{*}<1\right)=\sqrt{\frac{\sigma^{*}\left(1+x_{H}\right) L}{x_{H}}}-1=x^{*}=\sqrt{D}-1 \\
\Leftrightarrow L=L^{*}=\frac{x_{H} D}{\sigma^{*}\left(1+x_{H}\right)} .
\end{gathered}
$$

Note that the equilibrium probability of bringing a lawsuit $\left(\sigma^{*}\right)$ is affected by $L$.

Efficient level $x^{*}$ exceeds $x_{H}$. So far, we have assumed that the efficient level of care is located in the "fuzzy" zone, that is $x^{*}<x_{H}$. When we assume $x^{*} \geq x_{H}$, the auditor still performs zero care when investors do not bring a lawsuit, whereas he chooses level $\hat{x}^{h} \leq x_{H}$ with a lawsuit. Contrary to the basic model, there is no longer excessive care with a lawsuit and, if $x^{*}>x_{H}$ holds, there will necessarily be suboptimal care in equilibrium. In contrast to the basic model, overcompensation then has a beneficial effect since it reduces the level of suboptimal care. However, the assumption $x^{*}>x_{H}$ does not seem to be very realistic since it implies that auditors who choose suboptimal level $x_{H}$ will never be held negligent. Over time, the courts should learn that the negligence rule is too lenient. As a consequence, negligence should be extended to levels of care exceeding $x^{*}$. In the law and economics literature, we rarely observe the assumption $x^{*} \geq x_{H}$ (Shavell 2004).

Precise negligence rule. If the standard of due care is precisely and efficiently defined as $x^{S}=x^{*}$, the auditor will exert the standard of due care if investors bring a lawsuit for sure. By exerting $x^{S}$, no negligence, and hence no overcompensation, occurs. Thus, with a precise negligence rule, overcompensation does not induce excessive care. The regulator would therefore be able to avoid distortions through overcompensation by precisely defining the standard of due care. However, considering the complexity of audits, a precisely and efficiently defined standard is hard to establish. In the audit context, it seems to be more plausible to assume that the standard of due care is vaguely defined. 


\section{Reputation losses}

\subsection{Evidence}

If a firm publishes a wrongfully audited financial statement, the auditor may lose his reputation. Whereas there is strong evidence that client firms lose their reputation with wrongly audited financial statements, ${ }^{10}$ there is only little empirical literature on the reputation losses of audit firms, even though it has been known for many years that auditors are concerned about protecting their reputation capital (Benston 1975; Watts and Zimmermann 1983; Lim and Tan 2008). Reputation losses might be significant, as the liquidation of Arthur Andersen following the Enron scandal shows. Lennox (1999) demonstrates that larger UK auditors are more likely to be sued, but only smaller audit firms lose a considerable amount of clients when an accounting scandal occurs. Weber et al. (2008) ascertain that the percentage of clients that abandoned KPMG after the ComROAD accounting scandal in 2002 doubled to $15.7 \%$ after a 3-year average of $7.7 \%$. It is noteworthy that even though investors have not (yet) brought any lawsuits against Arthur Andersen or KPMG, significant reputation losses nevertheless occurred. To sum up: reputation losses are likely to affect audit firms even though there is scarce data on the quantitative effects.

\subsection{Model set-up}

We slightly modify the model assumptions set out in Sect. 2.1. First, in order to focus on the reputation effects, we skip the assumption on overcompensation and assume $m=1$. This simplification does not affect the qualitative results of the following analysis.

Second, in order to obtain interior solutions, we assume $F(x)$ to be non-concave and to be defined for $x \in[0, \infty)$.

$$
0 \leq F(x) \leq 1, \quad F^{\prime}(x)<0, F^{\prime \prime}(x) \geq 0 \quad F(x=0)=1, \quad F(x=\infty)=0 .
$$

\footnotetext{
10 Chaney and Philipich (2002) found that when the Enron scandal broke on January 10, 2002, the stocks of other Arthur Andersen clients suffered an abnormal return of $-1.88 \%$ in the 3 days after the revelation. Other clients of the Houston office of Arthur Andersen, which had audited Enron, show an abnormal performance of $-4.41 \%$. Karpoff et al. (2008) investigate the extent and sources of losses in the firm's value (measured by the loss in share price) for 585 firms targeted by SEC enforcement actions for financial misrepresentation from 1978 to 2002 . On average, firms lose $38 \%$ of their market value following a report on misconduct. Approximately, $24.5 \%$ of the market value loss can be attributed to the adjustment to the "true" value of the firm if there was no misrepresentation. Karpoff et al. (2008) approximate the effect on share prices, which results exclusively from revaluations in the balance sheet, by the product of the impairment of equity's book value and the median of the market-to-book value ratios of the relevant industry. Another $8.8 \%$ of the market value loss is due to legal penalties, including fines and settlements of securities class action lawsuits. Karpoff et al. (2008) argue that the remaining 66.6\% of the market value loss represents the loss of reputation. Hence, the loss of reputation is supposed to be about 7.5 times larger than the sum of fines and settlement payments. Reputation losses seem to be much more important than legal costs. It is also noteworthy that only $39 \%$ of the enforcement actions were accompanied by class action lawsuits. Thus, the majority of firms suffered a reputation loss outside litigation.
} 


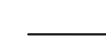

Good and bad auditors decide on level of care
Based on the audit report, damage occurs or not, investors update beliefs
Investors bring a

lawsuit or not

Fig. 1 Sequence of events

Recall that $F(x)$ captures the ex ante uncertainty that the court will decide on negligence ex post for a given level of care $x$. The probability of damage occurring, $p(x)$, is defined as in (1): $p=p(x)$ with $x \geq 0$; with $0 \leq p \leq 1, p(x=0)=1, p^{\prime}(x)<0$, $p^{\prime \prime}(x)>0$ and $p \rightarrow 0$, if $x \rightarrow \infty$.

Third, and most importantly, we address reputation concerns. There are two types of auditors. The good type $(G)$ provides high-quality audits, whereas the bad type $(B)$ provides low-quality audits. Quality will be endogenously determined by the auditors' direct audit costs and, hence, by the probability of damage occurring, $p\left(x_{i}\right), i \in$ $\{B, G\}$. We assume that good-quality auditors bear lower direct costs, possibly due to specialization (Gigler and Penno 1995). Direct audit costs are not observable.

The auditor's reputation loss refers to the present value of lost future rents from auditing and non-auditing services. The present value is a maximum of $R$ for an auditor who is unambiguously of the good type. There is common knowledge that, initially, the share of good auditors in the population is $\theta$ and the share of bad auditors is $1-\theta$ with $0<\theta<1$.

Investors update their beliefs in an auditor's quality when damage occurs due to a material error in an audited financial statement. Investors will then attach updated belief $\theta^{d}$ with $\theta^{d} \leq \theta$. If no damage occurs, the updated belief is $\theta^{\text {nd }}$ with $\theta^{\text {nd }} \geq \theta$. In case of damage, the auditor will then lose expected future rents of $\left(\theta-\theta^{d}\right) R$. This is in line with the Arthur Andersen failure and with the evidence provided by Weber et al. (2008). We derive updated beliefs endogenously in equilibrium.

The sequence of events is represented by the following Fig. 1.

\subsection{Analysis}

In what follows, we employ an upper bar to given values of variables, whereas stars indicate the equilibrium levels of variables. We start with the game-theoretical analysis right away. With a given suing probability $\bar{\sigma}$ and given posteriori beliefs $\bar{\theta}^{\text {nd }}$ and $\bar{\theta}^{d}$, the good auditor's cost function reads:

$$
\begin{gathered}
C\left(x_{i}\right)=b_{i} x+\bar{\sigma} F(x) p(x) D+p(x)\left(\theta-\bar{\theta}^{d}\right) R-[1-p(x)]\left(\bar{\theta}^{n d}-\theta\right) R, \\
i \in\{B, G\}, \quad b_{G}=1, \quad b_{B}>1 .
\end{gathered}
$$

The cost function consists of four terms. The first two terms denote the direct audit costs and the expected damage compensation. The latter two terms represent reputation effects. The event of damage induces investors to update their beliefs in the auditor's quality. Consequently, there is a loss in reputation. Damage occurs with probability 
$p(x)$. However, if no damage occurs, there is a gain in reputation which occurs with probability $1-p(x)$. The first derivative yields:

$$
\begin{gathered}
C^{\prime}\left(x_{i}\right)=b_{i}+\bar{\sigma}\left[F^{\prime}(x) p(x)+F(x) p^{\prime}(x)\right] D+p^{\prime}(x)\left(\bar{\theta}^{n d}-\bar{\theta}^{d}\right) R, \\
i \in\{B, G\}, b_{G}=1, b_{B}>1 .
\end{gathered}
$$

Since $p^{\prime}(x)<0$, the individual optimum $\hat{x}_{i}$ increases with expected reputation losses $\left(\bar{\theta}^{n d}-\bar{\theta}^{d}\right) R$-even in the absence of any litigation $(\bar{\sigma}=0)$. Note that the second term in (23.2) is negative since $F(x)$ and $p(x)$ are positive, but $F^{\prime}(x)$ and $p^{\prime}(x)$ have a negative sign. $C\left(x_{i}\right)$ has one interior minimum.

Due to different direct audit costs, the optimum level of care will be higher with the good auditor. Thus, the probability of damage differs between the two types, allowing for an update following the events that damage or no damage occurs. Therefore,

$$
\begin{aligned}
& \hat{x}_{G}>\hat{x}_{B} \quad \text { and } \theta^{n d}>\theta>\theta^{d} \\
& \text { with } \theta^{\text {nd }}=\frac{\theta\left[1-p\left(\hat{x}_{G}\right)\right]}{\theta\left[1-p\left(\hat{x}_{G}\right)\right]+(1-\theta)\left[1-p\left(\hat{x}_{B}\right)\right]} \\
& \quad \text { and } \theta^{d}=\frac{\theta \cdot p\left(\hat{x}_{G}\right)}{\theta \cdot p\left(\hat{x}_{G}\right)+(1-\theta) p\left(\hat{x}_{B}\right)}
\end{aligned}
$$

representing the updated beliefs when no damage occurs or when damage occurs, respectively. Note that even in the case where there is no lawsuit $(\bar{\sigma}=0)$, there still is an incentive to reduce the probability of damage occurring and the reputation loss attached to it, as the first derivative shows (see 23.2):

$$
C^{\prime}\left(x_{i}, \bar{\sigma}=0\right)=b_{i}+p^{\prime}(x)\left(\bar{\theta}^{n d}-\bar{\theta}^{d}\right) R, \quad i \in\{B, G\}, b_{G}=1, b_{B}>1 .
$$

That is, even without a lawsuit, the good and bad type will exert different levels of care such that reputation effects evolve. ${ }^{11}$

The social costs of an audit are now:

$$
K(x)=\left[\theta+(1-\theta) b_{B}\right] x+p(x) D \text { with } K^{\prime}(x)=\left[\theta+(1-\theta) b_{B}\right]+p^{\prime}(x) D .
$$

With the socially desirable level of care, $x=x^{*}$, marginal gains equal the marginal costs of auditing: $C^{\prime}\left(x=x^{*}\right)=0$. Both auditors will exert excessive care if the individual optimum of the bad type exceeds the social optimum, that is, if $x^{*}<\hat{x}_{B}<\hat{x}_{G}$.

\footnotetext{
11 Note that both auditors exerting zero care will not occur in equilibrium. The good type knows that he will gain in reputation by exerting marginally more care than the bad type. Due to the convex function $p(x)$, marginal reputation gains outweigh marginal care. The bad auditor responds by then increasing his level of care. As a consequence, both the good and bad type exert a positive level of care where individual marginal benefits equal individual marginal costs.
} 
In this case, the bad auditor's marginal net benefits of increasing care exceed the social marginal net benefits. According to (23.2) and (25), this will happen if for $x \geq 0$ the following holds ${ }^{12}$ :

$$
\begin{aligned}
& \bar{\sigma}\left|F^{\prime}(x) p(x)+F(x) p^{\prime}(x)\right| D+\left|p^{\prime}(x)\right|\left(\bar{\theta}^{n d}-\bar{\theta}^{d}\right) R-b_{B} \\
& >\left|p^{\prime}(x)\right| D-\left[\theta+(1-\theta) b_{B}\right] \\
& \Leftrightarrow\left(\bar{\theta}^{n d}-\bar{\theta}^{d}\right) R>D-\frac{\bar{\sigma}\left|F^{\prime}(x) p(x)+F(x) p^{\prime}(x)\right| D-\left(b_{B}-1\right) \theta}{\left|p^{\prime}(x)\right|} .
\end{aligned}
$$

Thus, if the reputation effects are sufficiently large, both auditors will exert excessive care. Note that excessive care is more likely with a higher suing probability $\bar{\sigma}$.

Proposition 4 There is an equilibrium with two subcases, depending on the size of transaction costs $T$.

Case 1 With high investors' transaction costs

$$
T \geq \theta^{d} F\left(\hat{x}_{G}(\sigma=0)\right) D+\left(1-\theta^{d}\right) F\left(\hat{x}_{B}(\sigma=0)\right) D
$$

there is a Nash equilibrium in pure strategies where investors do not sue and the auditors still perform positive care $\hat{x}_{G}>\hat{x}_{B}>0$ with $F\left(\hat{x}_{G}\right)<F\left(\hat{x}_{B}\right)<1$, implying an efficiency loss of $\theta\left[Y\left(x^{*}\right)-Y\left(\hat{x}_{G}(\sigma=0)\right)\right]+(1-\theta)\left[Y\left(x^{*}\right)-Y\left(\hat{x}_{B}(\sigma=0)\right)\right]$. Both auditors' level of care increases with the size of expected reputation losses and gains. The investors' updated beliefs in equilibrium when no damage occurs and when damage occurs are:

$$
\begin{aligned}
\theta^{n d^{*}}= & \frac{\theta\left[1-p\left(\hat{x}_{G}(\sigma=0)\right)\right]}{\theta\left[1-p\left(\hat{x}_{G}(\sigma=0)\right)\right]+(1-\theta)\left[1-p\left(\hat{x}_{B}(\sigma=0)\right)\right]} \\
& \text { and } \theta^{d *}=\frac{\theta \cdot p\left(\hat{x}_{G}(\sigma=0)\right)}{\theta \cdot p\left(\hat{x}_{G}(\sigma=0)\right)+(1-\theta) p\left(\hat{x}_{B}(\sigma=0)\right)},
\end{aligned}
$$

respectively.

Case 1a A bad auditor exerts efficient care and the good auditor takes excessive care even though investors do not bring a lawsuit if reputation effects are sufficiently strong defined as

$$
\left(\theta^{n d^{*}}-\theta^{d^{*}}\right) R=D+\frac{\left(b_{B}-1\right) \theta}{p^{\prime}\left(x_{B}^{*}\right)} .
$$

The efficiency loss then amounts to $\theta\left[Y\left(x^{*}\right)-Y\left(\hat{x}_{G}\right)\right]$.

$\overline{12}$ Recall that both $p^{\prime}(x)$ and $F^{\prime}(x)$ have a negative sign, but $p(x)$ and $F(x)$ are positive. 
Case 2 With low investors' transaction costs, that is, if (27) does not hold, there is a Nash equilibrium where investors sue with probability $\sigma^{*}=1$ if $\hat{x}_{G}(\sigma=1) \leq \underline{x}^{13}$ and with probability $\sigma^{*}<1$ if $\hat{x}_{G}(\sigma=1)>\underline{x} . \underline{x}$ denotes the level of care where the marginal costs of a lawsuit equal the marginal benefits:

$$
F(\underline{x})\left[\theta^{d^{*}} D+\left(1-\theta^{d^{*}}\right) D\right]=F(\underline{x}) D=T .
$$

In equilibrium, auditors choose a pure strategy where the good auditor's level of care is higher:

$$
\hat{x}_{G}\left(\sigma^{*}\right)>\hat{x}_{B}\left(\sigma^{*}\right)>0 \text {. }
$$

For a given suing probability, both auditors' level of care increases with the size of expected reputation losses and gains. The investors' updated beliefs in equilibrium when no damage occurs and when damage occurs are:

$$
\begin{aligned}
\theta^{n d^{*}}= & \frac{\theta\left[1-p\left(\hat{x}_{G}\left(\sigma^{*}\right)\right)\right]}{\theta\left[1-p\left(\hat{x}_{G}\left(\sigma^{*}\right)\right)\right]+(1-\theta)\left[1-p\left(\hat{x}_{B}\left(\sigma^{*}\right)\right)\right]} \\
& \text { and } \theta^{d *}=\frac{\theta \cdot p\left(\hat{x}_{G}\left(\sigma^{*}\right)\right)}{\theta \cdot p\left(\hat{x}_{G}\left(\sigma^{*}\right)\right)+(1-\theta) p\left(\hat{x}_{B}\left(\sigma^{*}\right)\right)},
\end{aligned}
$$

respectively. The efficiency loss amounts to $\sigma^{*} T+\theta\left[Y\left(x^{*}\right)-Y\left(\hat{x}_{G}\left(\sigma^{*}\right)\right)\right]+(1-\theta)$ $\left[Y\left(x^{*}\right)-Y\left(\hat{x}_{B}\left(\sigma^{*}\right)\right)\right]$.

Proof case 1 and case 2: See (23.1)-(26). Proof: case 1a: With the efficient level, $C^{\prime}\left(x^{*}\right)=1+p^{\prime}\left(x^{*}\right) D=0$ holds. Given that $\sigma=0$, setting $C^{\prime}\left(x^{*}\right)=C^{\prime}\left(x_{B}\right)$ and using (24.1), we obtain (29). See also (26) by assuming $\bar{\sigma}=0$.

Proposition 4 contains several important messages. First, regardless of whether there is a lawsuit or not, the good type will exert a higher level of care than the bad type. Two assumptions drive this result: the marginal costs of providing higher care are lower and investors rationally update their beliefs when damage or no damage occurs. If either marginal costs were the same, both types would not differ with regard to the level of care chosen. Consequently, no reputation effects occur.

Second, reputation effects improve both the good and the bad auditor's incentive to take care even in the absence of litigation.

Third and most importantly, as case 1a in Proposition 4 suggests, sufficiently strong reputation effects may induce a novel type of equilibrium where investors do not bring a lawsuit and auditors still perform efficient or greater care. This is interesting from a methodological point of view, but especially from an economics perspective. Even in the absence of litigation, reputation concerns might induce efficient care. Reputation concerns also explain why we do not observe zero auditor care in countries where investors have very poor incentives to bring a lawsuit.

13 Basically, it needs two conditions: $\hat{x}_{G}(\sigma=1) \leq \underline{x}$ and $\hat{x}_{B}(\sigma=1) \leq \underline{x}$. However, since in this case $\hat{x}_{G}>\hat{x}_{B}$ holds, $\hat{x}_{G}(\sigma=1) \leq \underline{x}$ is more restrictive. 
This brings us to the question of when a liability cap is desirable and when it is at all effective. If reputation effects are too large, both auditors will perform excessive care if (26) holds. If (26) holds, a properly defined liability cap $L^{* *}$ generally mitigates excessive care and will even induce efficient care with the bad type in equilibrium if the following holds:

$$
\begin{aligned}
\sigma^{*} & \left|F^{\prime}\left(x_{B}^{*}\right) p\left(x_{B}^{*}\right)+F\left(x_{B}^{*}\right) p^{\prime}\left(x_{B}^{*}\right)\right| L^{* *}+\left|p^{\prime}\left(x_{B}^{*}\right)\right|\left(\theta^{n d^{*}}-\theta^{d^{*}}\right) R-b_{B} \\
= & \left|p^{\prime}\left(x_{B}^{*}\right)\right| D-\left[\theta+(1-\theta) b_{B}\right] \\
\Leftrightarrow L^{* *} & =\frac{\left|p^{\prime}\left(x_{B}^{*}\right)\right|\left[D-\left(\theta^{n d^{*}}-\theta^{d^{*}}\right) R\right]+\left(b_{B}-1\right) \theta}{\sigma^{*}\left|F^{\prime}\left(x_{B}^{*}\right) p\left(x_{B}^{*}\right)+F\left(x_{B}^{*}\right) p^{\prime}\left(x_{B}^{*}\right)\right|}
\end{aligned}
$$

with $L^{* *} \in[0, D), \theta^{j^{*}}=\theta^{j^{*}}\left(L^{* *}\right), j \in\{n d, d\}$.

Note that a liability cap requires a sufficiently high suing probability in equilibrium $\left(\sigma^{*}\right)$ such that there is excessive care and $L^{* *}<D$ holds. The condition (33) also indicates that, with increasing reputation effects, the liability cap should be lower. Since the threat of the loss of reputation becomes more severe, the sanction of damage compensation becomes less important in order to properly motivate auditors. Reputation losses and liability can be seen as complementary.

However, if reputation effects are too large, excessive care can no longer be offset by a liability cap. In technical terms, this is the case when the numerator in (33) becomes negative, that is, when the following holds:

$$
\left(\theta^{n d^{*}}-\theta^{d^{*}}\right) R>D+\frac{\left(b_{B}-1\right) \theta}{\left|p^{\prime}\left(x_{B}^{*}\right)\right|} .
$$

The larger rents $R$ are from audit and non-audit services and the greater the difference $\theta^{n d^{*}}-\theta^{d^{*}}$, the more likely it is that condition (34) will hold. That is, the more the good and the bad type's levels of care differ. Note that condition (34) holds independently of the probability of suing, that is, even when investors do not bring a lawsuit at all.

Proposition 5 When auditors exert excessive care in equilibrium with unlimited liability, a properly defined liability cap $L^{* *}<D$ is useful to generally mitigate excessive care and to induce efficient care with the bad auditor type. If reputation effects are too strong, a liability cap will not help to induce efficient care.

Proof See (33) and (34).

\subsection{Discussion}

Precise negligence rule With a precisely and efficiently defined negligence rule, we obtain similar qualitative results. If transaction costs are too high and reputation effects are modest, investors will not bring a lawsuit and both types of auditors will perform suboptimal but non-zero care. The good type exerts more care than the bad type. If transaction costs are low and reputation effects are quite modest, both auditors 
will randomize strategies, choosing suboptimal care with some probability. With the counter-probability, both auditors exert the efficient standard of due care. Since the two auditor types choose different levels of care with only some probability, reputation effects are endogenously limited.

If reputation effects are sufficiently strong, both types of auditors perform excessive care even when transaction costs deter investors from bringing a lawsuit. Again, a properly defined liability cap is able to mitigate excessive care and might even induce efficient care with one auditor type if reputation effects are not too strong.

How can the regulator influence reputation losses? The regulator might want to restrict liability exposure for other reasons not addressed in this model, such as limited insurability. Proposition 5 suggests that auditors' incentives might still not be distorted by limited liability if the regulator manages to properly increase reputation effects, that is, to increase the present value of the rents from auditing and non-auditing services $R$. One way would be to renounce the separation of audit and non-audit business. Another way would be to decrease the level of competition in the audit market by different means. ${ }^{14}$ Of course, the latter proposal would face the cost of monopoly or oligopoly dead-weight losses. However, it would still be worthwhile if those costs were lower than the marginal efficiency losses due to suboptimal auditor care. These arguments are based purely on economic reasoning, neglecting political feasibility.

\section{Conclusion}

This paper addresses the issue of how potential reputation losses and overcompensation affect auditors' incentives to take care. When there is a material error in an audited financial statement, some investors suffer losses, whilst others benefit from it. Damage compensation payments to losing investors usually exceed the social damage of all investors (overcompensation). It transpires that under a negligence rule with a vaguely defined standard of due care, overcompensation may cause or exacerbate excessive care when there is no properly defined liability cap.

We also explore reputation losses suffered by an auditor of a wrong financial statement. Reputation losses are defined as the present value of lost future rents from auditing and non-auditing services. An auditor may also gain in reputation if the audit was correct. Both the potential losses and the potential gains of reputation strengthen the auditors' incentives to exert a higher level of care.

We assume that good auditors bear lower marginal direct audit costs than bad auditors. Good auditors therefore exert more care, lowering the probability of a wrong audit and of investors' damage. If investors rationally update beliefs when damage or no damage occurs, reputation effects will occur and will improve the auditors' incentives ex-ante. When reputation effects are sufficiently strong, an equilibrium in pure strategies evolves where investors do not bring a lawsuit and auditors do not exert suboptimal care. Litigation costs are then saved. If reputation effects are too strong,

14 also increases as the interest rate decreases. 
they induce excessive care. A properly defined liability cap then mitigates excessive care.

We argue that the liability system should take overcompensation and reputation concerns into account. Our analysis suggests that if reputation losses outside litigation are significant, auditors will have proper incentives to exert sufficient care even if investors do not sue.

Future research should especially address empirical issues. Only little is known about the size of auditors' reputation losses and the factors that determine them. From a theoretical point of view, the model could be extended by updated beliefs when courts decide on negligence. Further, the possibility of settlement and court errors has not been explored in this setting yet. The model may also be extended to a multi-period setting such that reputation effects are addressed more appropriately.

\section{Appendix: Overcompensation: why private loss exceeds social loss}

In the following, we show why individual loss exceeds the social loss with auditor liability, and derive the factors determining this gap (see Bigus and Schäfer 2007). We consider a publicly traded firm listed on a semi-strong efficient stock market. Investors (shareholders) are risk-neutral. The present value of the cash flow related to each share is $a(a>0)$ in each period. The interest rate for safe investments equals $r(r>0)$. The present value of the cash flow is risky, and might be low or high: $a \in\left\{a_{L}, a_{H}\right\} ; a_{L}<$ $r<a_{H}$. A cash flow of $a_{L}$ is related to a situation of financial distress.

Investors do not know future cash flows precisely. Let us assume that the present value of cash flows from period 2 on equals $A$. In $t=0$, the period 1 cash flow is also risky; $\pi$ denotes the ex-ante probability of financial distress occurring. A share price in $t=0$ is supposed to equal the present value of future cash flows:

$$
\text { Price }=\pi \cdot a_{L}+(1-\pi) a_{H}+A=\bar{a}+A
$$

where $\pi$ is the likelihood of the firm being in financial distress. We assume $\bar{a}>r$, such that the mean cash flow from the firm exceeds the return of the safe investment opportunity.

In $t=0$, the management knows that the firm is in financial distress, but is able to hide this information from investors until $t=1$. If investors knew of the distress, they would invest in the safe investment. Thus, in case of financial distress, each investor will lose $r-a_{L}$ unless financial distress is revealed immediately in $t=0$. Figure 2 shows the sequence of events.

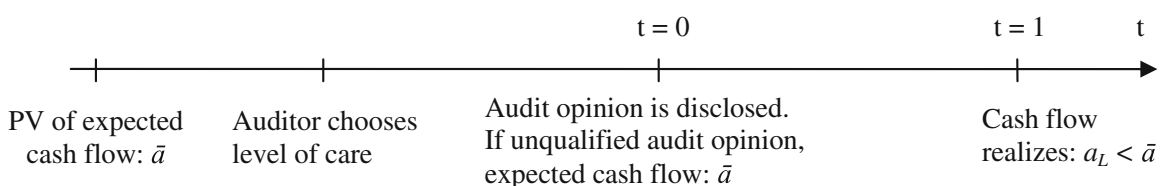

Fig. 2 Sequence of events 
Under these assumptions, a correct audit is useful. Let us assume that an auditor will disclose financial distress by a qualified audit opinion (e.g., due to a violation of the going concern assumption). Investors will then shift investments and will lose $\bar{a}-r$. With an unqualified audit opinion, investors will not change their mind and will lose more, namely $\bar{a}-a_{L}$.

The audit is useful in the bad state of nature, which occurs with probability $\pi$. The welfare gain of an audit is reflected by $Y$ :

$$
Y=p(x) \pi\left(r-a_{L}\right)-x .
$$

The expected damage (per share) from the wrong audit is reflected by the term $\pi$ ( $r-$ $a_{L}$ ). Now we want to clarify the issue of overcompensation. With many liability regimes, e.g., with the Birnbaum rule in the US, the wrong-doing auditor has to compensate the individual damage of investors who suffered losses from the wrong audit. Individual damage equals the difference between the initial purchasing price of the stock, and the price after financial distress reveals: $(\bar{a}+A)-\left(a_{L}+A\right)=\bar{a}-a_{L}$. Note that damage compensation exceeds the social loss per share: $\bar{a}-a_{L}>r-a_{L}$. The loss exceeding the social loss $(\bar{a}-r)$ is a gain to another investor, who was able to sell the share at a price of $\bar{a}+A$ even though $a_{L}+A$ is the fair value of the share. We are not aware of any legal system that requires "winning" investors to transfer such gains to "losing" investors. Consequently, the loss exceeding the social loss $(\bar{a}-r)$ is distributional in nature, but does not relate to the social loss from the wrong allocation of funds $\left(r-a_{L}\right)$ caused by the wrong audit.

In the main body of this paper, we implicitly define the social loss as $D=$ $n\left(r-a_{L}\right)$, where $n$ is the number of shares. Accordingly, individual loss is implicitly defined as $m D=n\left(\bar{a}-a_{L}\right)$, which implies $m=\frac{\bar{a}-a_{L}}{r-a_{L}}$. Note that the level of overcompensation, $m$, is not related to punitive damages or to the allocation of lawyer's and court fees. Further, for simplification we assume $\pi=1$.

Proof of Proposition 3, case 2: For a given probability of suing $\sigma(0<\sigma \leq 1)$, the auditor's expected total costs in $t=0$ amount to:

$$
\begin{aligned}
C(x) & =x+\sigma p(x) F(x) m D+(1-\sigma) F(x) p(x) \cdot 0 \\
& =x+\sigma\left[\frac{x_{H}-x}{x_{H}} \frac{m D}{1+x}\right] \text { with } \\
C^{\prime}(x) & =1-\left[\frac{\sigma\left(1+x_{H}\right) m D}{x_{H}(1+x)^{2}}\right] .
\end{aligned}
$$

Given that investors bring a lawsuit with a probability of $\sigma$, the individual global cost minimum is then:

$$
\hat{x}(\sigma)=\sqrt{\frac{\sigma\left(1+x_{H}\right) m D}{x_{H}}}-1 .
$$

Whether investors will sue in $t=1$ depends on the expected benefits of the lawsuit, which, in turn, are determined by the auditor's level of care. Investors are indifferent 
to suing and not suing with a level of care of $x=\underline{x}$, where the marginal costs of a lawsuit equal the marginal benefits:

$$
F(\underline{x}) m D=T \quad \Leftrightarrow \frac{x_{H}-\underline{x}}{x_{H}} m D=T \quad \Leftrightarrow \underline{x}=x_{H}-\frac{x_{H} T}{m D} .
$$

Note that $\underline{x}<x_{H}$. Investors bring a lawsuit for sure $(\sigma=1)$ if $\hat{x}(\sigma=1) \leq \underline{x}$ holds in equilibrium. If $\hat{x}(\sigma=1)>\underline{x}$ holds, investors will choose a mixed strategy and will sue with a probability of $\sigma^{*}$ in equilibrium such that $\hat{x}\left(\sigma^{*}<1\right)=\underline{x}$ holds (Ewert 1999).

\section{References}

Antle R (1982) The auditor as an economic agent. J Account Res 20:503-527

Ashbaugh H, LaFond R, Mayhew BW (2003) Do nonaudit services compromise auditor independence? Further evidence. Account Rev 78:611-639

Balachandran B, Nagarajan N (1987) Imperfect information, insurance, and auditors' legal liability. Contemp Account Res 3:281-301

Benston G (1975) Accountants' integrity and financial reporting. Financ Exec 10-14

Bigus J, Schäfer H-B (2007) Die Haftung des Wirtschaftsprüfers am Primärmarkt und am Sekundärmarkteine rechtsökonomische Analyse. Z Betr 77:19-49

Boritz J, Zhang P (1997) The implications of alternative litigation cost allocation systems for the value of audits. J Account Audit Finance 12:353-372

Chaney P, Philipich K (2002) Shredded reputation: the cost of audit failure. J Account Res 40:1221-1245

Clatworthy MA, Peel MJ (2007) The effect of corporate status on external audit fees: evidence from the UK. J Bus Finance Account 34:169-201

Committee on Capital Markets Regulation (2006) Interim report of the Committee on Capital Markets Regulation. Cambridge

Craswell R, Calfee J (1986) Deterrence and uncertain legal standards. J Law Econ Organ 2:279-303

Dari Mattiacci G, Schäfer H-B (2007) The case of pure economic loss. Int Rev Law Econ 27:8-28

Datar S, Alles M (1999) The formation and role of reputation and litigation in the auditor-manager relationship. J Account Audit Finance 14:401-428

Dye R (1993) Auditor standards, legal liability, and auditor wealth. J Political Econ 101:887-914

European Commission (2000) Commission recommendation concerning the limitation of the civil liability of statutory auditors and audit firms. Brussels, 5 June 2008

Ewert R (1999) Auditor liability and the precision of auditing standards. J Inst Theor Econ 155:181-206

Ewert R, Feess E, Nell M (2000) Auditor liability rules under imperfect information and costly litigation: the welfare-increasing effect of liability insurance. Eur Account Rev 9:371-385

Gigler F, Penno M (1995) Imperfect competition in audit markets and its effects on the demand for auditrelated services. Account Rev 70:317-336

Hillegeist St (1999) Financial reporting and auditing under alternative damage apportionment rules. Account Rev 74:347-369

Karpoff J, Lee D, Martin G (2008) The cost to firms of cooking the books. J Financ Quant Anal 43:581-612

Lennox C (1999) The relationship between auditor accuracy and auditor size: an evaluation of reputation and deep pockets arguments. J Bus Finance Account 26:779-806

Lim CY, Tan H-T (2008) Non-audit service fees and audit quality: the impact of auditor specialization. J Account Res 46(1):199-246

London Economics, Ewert R (2006) Study on the economic impact of auditors' liability regimes. Final report to EC-DG internal market and services. Brussels/London 2006. http://ec.europa.eu/internal_market/ auditing/liability/index_de.htm

Niblett A, Posner R, Shleifer A (2008) The evolution of a legal rule. Working paper University of Chicago, Harvard University, February 2008

O'Malley S (1993) Legal liability is having a chilling effect on the auditor's role. Account Horiz 7:82-87 
Pae S, Yoo S-W (2001) Strategic interaction in auditing: an analysis of auditors' legal liability, internal control system quality, and audit effort. Account Rev 76:333-356

Polinsky M, Rubinfeld D (1996) Optimal awards and penalties when the probabilities of prevailing varies among plaintiffs. Rand J Econ 27:269-280

Radhakrishnan S (1999) Investors' recovery friction and auditor liability rules. Account Rev 74:225-240

Schwartz R (1997) Legal regimes, audit quality and investment. Account Rev 72:385-406

Shavell S (1987) Economic analysis of accident law. Harvard University Press, Cambridge

Shavell S (2004) Foundations of economic analysis of law. Harvard University Press, Cambridge

Smith R, Tidrick D (1998) The effect of alternative judicial systems and settlement on auditing. Rev Account Stud 2:353-381

Watts R, Zimmermann J (1983) Agency problems, auditing, and the theory of the firm: some evidence. J Law Econ 25:613-633

Weber J, Willenborg M, Zhang J (2008) Does auditor reputation matter? The case of KPMG Germany and ComROAD AG. J Account Res 46:941-972

Willekens M, Simunic D (2007) Precision in auditing standards: effects on auditor and director liability and the supply and demand for audit services. Account Bus Res 37:217-232

Zhang P, Thoman L (1999) Pre-trial settlement and the value of audits. Account Rev 74:473-491 